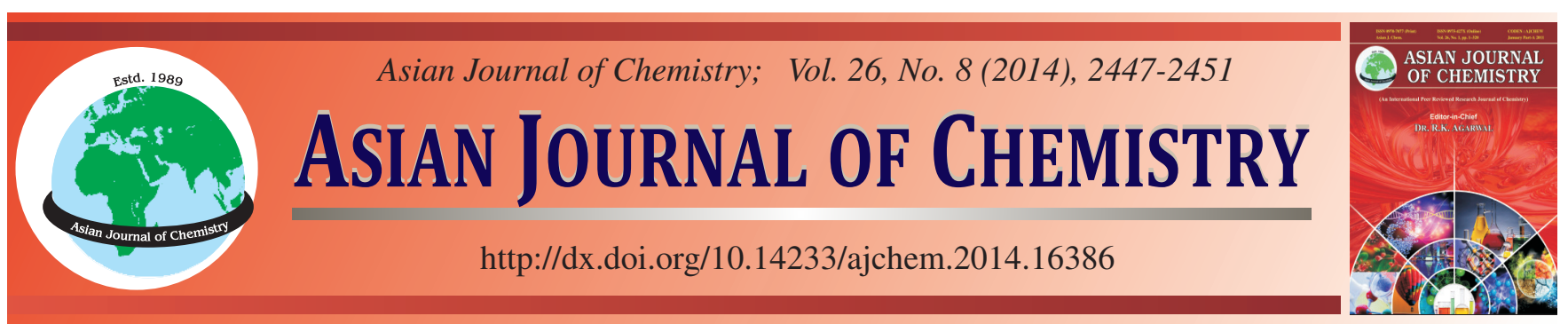

\title{
Theoretical Study of Intermolecular Hydrogen Bonding and Interaction in Ethylene Glycol-Water Mixtures
}

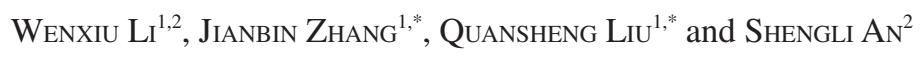

${ }^{1}$ College of Chemical Engineering, Inner Mongolia University of Technology, Huhhot 010051, China

${ }^{2}$ School of Coal Science and Engineering, Inner Mongolia University of Science and Technology, Baotou 014014, P.R. China

*Corresponding authors: Tel/Fax: +86 10 62751529; E-mail: tadzhang@pku.edu.cn, liuqs@imut.edu.cn

Aqueous solution of ethylene glycol (EG) were used in the $\mathrm{SO}_{2}$ absorption processes. Meanwhile, the various spectra suggested that aqueous solution of ethylene glycol can bond with $\mathrm{SO}_{2}$ by the mean of hydrogen bonding and interaction. It is therefore important to understand the interaction of ethylene glycol with $\mathrm{H}_{2} \mathrm{O}$ at the molecular level. In this work, the ground-state structure and energies of ethylene glycol, $\mathrm{H}_{2} \mathrm{O}, \mathrm{EG}_{2}-\mathrm{H}_{2} \mathrm{O}$ and $\mathrm{EG} / \mathrm{H}_{2} \mathrm{O}_{1-3}$ hydrogen bonded clusters were investigated using density functional theory (DFT). Calculated IR spectra, dipole moments and rotational constants for all optimum conformers at the same level are provided for comparison with the experiments. The binding energies $\left(-\mathrm{D}_{\mathrm{e} 0}\right)$ and the calculated harmonic vibrational frequencies for ethylene glycol and $\mathrm{H}_{2} \mathrm{O}$ are in good agreement with previous calculated and experimental results. The $-\mathrm{D}_{\mathrm{e} 0}$ values for ethylene glycol $+\mathrm{H}_{2} \mathrm{O}$ shows that the addition of $\mathrm{H}_{2} \mathrm{O}$ can disrupt the original hydrogen bonds in ethylene glycol system and ethylene glycol can be easily solved in water.

Keywords: Hydrogen Bonding and Interaction, Ethylene Glycol, Water, Density Functional Theory (DFT).

\section{INTRODUCTION}

Sulfur dioxide $\left(\mathrm{SO}_{2}\right)$ is an important atmospheric pollutant and therefore it is important in environmental protection. In recent years, there is a growing interest in the use of organic solvents for removal of $\mathrm{SO}_{2}$ and organic solvents used as absorbents have been identified as an option among the regenerative process $^{1-5}$ because regeneration can be done by pressure reduction, by temperature increase and by use of a carrier gas. Of the numerous organic solvents, alcohols show favorable absorption and desorption capabilities for acid gases in industrial proce$\operatorname{sses}^{6}$. Therefore, our research group has paid great attention to alcohol + water system for removal of $\mathrm{SO}_{2}$ for several years ${ }^{7-10}$.

In the recent work ${ }^{11}, \Phi_{1}=$ (70 to 90$) \%$ (volume fraction of ethylene glycol in aqueous solutions of ethylene glycol) showed stronger capacity to grasp $\mathrm{SO}_{2}$. Aqueous solutions of ethylene glycol present native hydrogen bonding sites for the absorption of $\mathrm{SO}_{2}$ so that the absorption and desorption properties of $\mathrm{SO}_{2}$ in aqueous solutions of ethylene glycol ${ }^{12,13}$ may be related to hydrogen bonding and interaction ${ }^{14-16}$ among molecules.

It is therefore important to understand the competition between hydrogen bonding and interactions involving ethylene glycol and $\mathrm{H}_{2} \mathrm{O}$ at the molecular level. The purpose of the present computational work is, therefore, to elucidate the hydrogen bonding and interaction between ethylene glycol and $\mathrm{H}_{2} \mathrm{O}$.

\section{EXPERIMENTAL}

All quantum chemical calculations were carried out with the Gaussian 03 suite of programs, using reasonable $6-31+\mathrm{G}(3 \mathrm{~d}, 3 \mathrm{p})$ and $6-311+\mathrm{G}(3 \mathrm{~d}, 3 \mathrm{p})$ basis sets and density functional theory (DFT) with the composite B3LYP exchange correlation functional and 6-31 + G (3d, 3p) and 6-311 + G $(3 d, 3 p)$ basis sets. Frequency calculations were performed following each optimization to obtain the zero point energy (ZPE) and IR spectral data. The binding energies $\left(-\mathrm{D}_{\mathrm{e} 0}\right)$ of clusters were calculated with respect to the separate molecules at the same level. For a given cluster, the binding energy, $-D_{e}$ ( $\mathrm{kcal} / \mathrm{mol})$ and ZPE corrected binding energies, - $\mathrm{D}_{\mathrm{e} 0}(\mathrm{kcal} /$ mol), were determined as a difference between the total energies of the clusters and the sum of the total energies of the isolated monomers contained in the clusters as follows:

$$
\begin{gathered}
\mathrm{E}_{\text {bind }}=-\mathrm{D}_{\mathrm{e}}=\mathrm{E}_{\mathrm{A}}+\mathrm{E}_{\mathrm{B}}-\mathrm{E}_{\mathrm{AB}} \\
\mathrm{E}_{\text {bind }, 0}=-\mathrm{D}_{\mathrm{e} 0}=\mathrm{E}_{\mathrm{A}, 0}+\mathrm{E}_{\mathrm{B}, 0}-\mathrm{E}_{\mathrm{AB}, 0}
\end{gathered}
$$

The $-D_{e}$ and $-D_{e 0}$ values for a trimer or a tetramer are defined similarly.

\section{RESULTS AND DISCUSSION}

Various possible structures of ethylene glycol/ $\mathrm{H}_{2} \mathrm{O}_{1-3}$ hydrogen bonded clusters are optimized and all optimum geometric structures are presented. 


\section{Ethylene glycol monomer and ethylene glycol dimer}

Ethylene glycol monomer: The most stable conformer of ethylene glycol is reported as tGg' conformer ${ }^{17}$. In this work, the intramolecular $\mathrm{H} \cdots \mathrm{O}$ bond length in the $\mathrm{tGg}^{\prime}$ is in the range of (2.389 to 2.405) $\AA$ under the B3LYP/6-31 and B3LYP/6311 level, which is reported as $2.362 \AA$ in $\mathrm{ref}^{18}$. (NLSD/DZVP2 level) and $2.3605 \AA$ in $\operatorname{ref}^{19}$. (QCISD/6-311 + + G (2d, 2p) level). In the $\mathrm{tGg}^{\prime}$, the intramolecular $\mathrm{HB}$ conformation is comprised of a five-membered quasi-ring and the $\mathrm{HB}$ is expected to be weak $^{16}$.

In Table-1, the total dipole moments for the geometries optimized with the same basis set are listed for conformers along with the experimentally determined dipole moments. In this work, the dipole moment of $\mathrm{tGg}^{\prime}$ is found in the range of (2.42 to 2.71) D, which were reported in the range of $(2.65$ to 2.74$) \mathrm{D}^{18-21}$. From Table-1, three rotational constants (GHZ) for conformer 1 (Fig. 1, (1)) calculated in this work are higher than the experimental values ${ }^{15,18}$.

Table-2 showed that the computational stretching and bending vibrational frequencies at the $6-31+\mathrm{G}(3 \mathrm{~d}, 3 \mathrm{p})$ and $6-31++\mathrm{G}(3 \mathrm{~d}, 3 \mathrm{p})$ levels are in good agreement with previous experimental results ${ }^{11,12}$.

We present that the values of other bond lengths, bond angles and dihedral angles not given here are available upon request. The intramolecular $\mathrm{H} \cdots \mathrm{O}$ bond length in the ethylene glycol monomer is $2.3885 \AA$. The studies of Howard et $a .^{22}$. have primarily focused on the lowest energy conformer; however, the Fig. 1 (1) conformer has been identified in the rotational spectra $^{20,23}$.

Ethylene glycol dimer: The intramolecular $\mathrm{H} \cdots \mathrm{O}$ bond lengths of ethylene glycol molecules in the ethylene glycol dimer are determined at $2.8362 \AA$ and $2.8395 \AA$ in this work, which were reported at $2.75 \AA$ and $2.78 \AA$ at the DFT B3LYP/

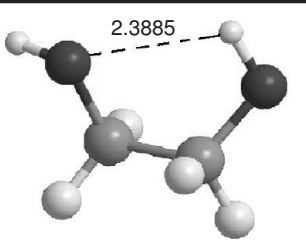

1

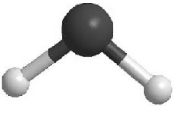

3

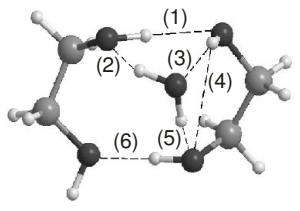

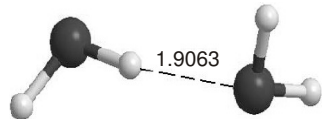

4

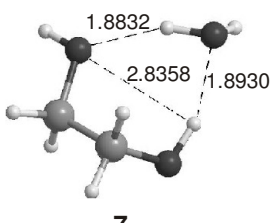

7

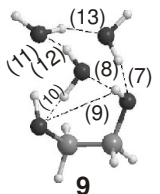

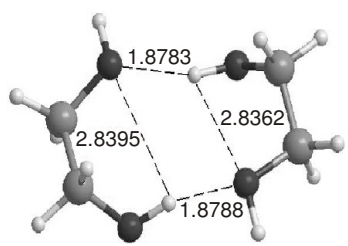

2
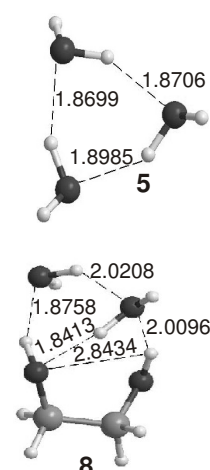

8
Fig. 1. Species involved in hydrogen bonding and interaction calculation. Bond lengths are in $\AA$. The dashed lines indicate the possible hydrogen bonding and interaction. Part possible hydrogen bond lengths: (1) $1.8925 \AA$; (2) $2.2305 \AA$; (3) $1.8589 \AA$; (4) $2.86385 \AA$; (5) $1.9523 \AA$; (6) $1.8456 \AA$; (7) $1.7429 \AA$; (8) $1.8175 \AA$; (9) 2.8039 ̊; (10) $2.2892 \AA$; (11) $1.9242 \AA$; (12) $2.0093 \AA$; (13) $1.7443 \AA$

6-311g (3df, 3pd) level ${ }^{24}$. The intermolecular H...O bond lengths of ethylene glycol molecules in the ethylene glycol dimer are determined at $1.8783 \AA$ and $1.8788 \AA$, which are in agreement with the values of $1.86 \AA$ and $1.89 \AA$ calculated at the DFT B3LYP/6-311g (3df, 3pd) level ${ }^{24}$.

TABLE-1

\begin{tabular}{|c|c|c|c|c|c|c|c|c|}
\hline & \multicolumn{8}{|c|}{$\begin{array}{r}\text { TABLE-1 } \\
\text { ELECTRONIC ENERGIES, DIPOLE MOMENTS, AND R }\end{array}$} \\
\hline & Species & Ee (a.u.) & ZPE (kcal/mol) & $\mathrm{E}_{0}$ (a.u.) & Dipole (Debye) & Rot & nal Constan & (GHZ) \\
\hline 1 & EG & $\begin{array}{l}-230.25985 \\
-228.59245^{\mathrm{a}} \\
-229.87192^{\mathrm{b}} \\
-229.61002^{\mathrm{c}} \\
-229.77942^{\mathrm{d}} \\
-229.75834^{\mathrm{e}}\end{array}$ & $\begin{array}{l}53.58 \\
55.21^{\mathrm{b}} \\
52.29^{\mathrm{e}}\end{array}$ & -230.17452 & $\begin{array}{l}2.7055 \\
2.7396^{\mathrm{c}} \\
2.65^{\mathrm{f}} \\
2.71^{\mathrm{d}}\end{array}$ & $\begin{array}{l}15.30873 \\
15.21460^{\mathrm{b}} \\
15.127 \\
(\text { exptl. } \\
14.920^{\mathrm{f}}\end{array}$ & $\begin{array}{l}5.54897 \\
5.53833^{\mathrm{b}} \\
5.311 \\
\left(\text { exptl. }^{\mathrm{f}}\right. \\
5.507^{\mathrm{f}}\end{array}$ & $\begin{array}{l}4.58297 \\
4.59503^{\mathrm{b}} \\
4.412 \\
\left.\text { (exptl. }^{\mathrm{f}}\right)^{\mathrm{f}} \\
4.524^{\mathrm{f}}\end{array}$ \\
\hline 2 & EG $\cdots$ EG & $\begin{array}{l}-460.53248 \\
-459.23021^{c}\end{array}$ & 109.00 & -460.35878 & $\begin{array}{l}1.7182 \\
1.625^{\mathrm{c}} \\
3.83-4.09^{\mathrm{g}}\end{array}$ & 2.53343 & 1.05119 & 0.80422 \\
\hline 3 & $\mathrm{H}_{2} \mathrm{O}$ & $\begin{array}{l}-76.42257 \\
-76.23311^{\mathrm{d}} \\
-76.46333^{\mathrm{i}}\end{array}$ & $\begin{array}{l}13.24 \\
13.3^{\mathrm{i}}\end{array}$ & $\begin{array}{l}-76.40148 \\
-76.43405^{\mathrm{i}}\end{array}$ & $\begin{array}{l}2.2491 \\
2.05^{\mathrm{d}} \\
1.856^{\mathrm{h}}\end{array}$ & 820.87618 & 421.46016 & 278.48063 \\
\hline 4 & $\mathrm{H}_{2} \mathrm{O} \cdots \mathrm{H}_{2} \mathrm{O}$ & $\begin{array}{l}-152.85541 \\
-152.93429^{i}\end{array}$ & $\begin{array}{l}28.99 \\
29.1^{\mathrm{i}}\end{array}$ & $\begin{array}{l}-152.80923 \\
-152.87772^{i}\end{array}$ & 2.9007 & 212.85038 & 6.55614 & 6.55275 \\
\hline 5 & $\mathrm{H}_{2} \mathrm{O} \cdots \mathrm{H}_{2} \mathrm{O} \cdots \mathrm{H}_{2} \mathrm{O}$ & $\begin{array}{l}-229.29827 \\
-229.41364^{\mathrm{i}}\end{array}$ & $\begin{array}{l}45.93 \\
45.9^{i}\end{array}$ & $\begin{array}{l}-229.22512 \\
-229.33077^{i}\end{array}$ & 1.2346 & 7.01387 & 6.89139 & 3.54654 \\
\hline 6 & $(\mathrm{EG})_{2} \cdots \mathrm{H}_{2} \mathrm{O}$ & -536.97384 & 125.68 & -536.77356 & 5.2739 & 1.65618 & 0.87820 & 0.77308 \\
\hline 7 & $\mathrm{EG} \cdots \mathrm{H}_{2} \mathrm{O}$ & $\begin{array}{l}-306.69677 \\
-306.08899^{d} \\
-306.97240^{\mathrm{e}}\end{array}$ & 69.59 & -306.58593 & $\begin{array}{l}3.9243 \\
3.72^{\mathrm{d}}\end{array}$ & 4.88867 & 3.48921 & 2.20339 \\
\hline 8 & $\mathrm{EG} \cdots\left(\mathrm{H}_{2} \mathrm{O}\right)_{2}$ & -383.13587 & 85.98 & -382.99891 & 1.7273 & 3.03288 & 1.93224 & 1.71296 \\
\hline 9 & $\mathrm{EG} \cdots\left(\mathrm{H}_{2} \mathrm{O}\right)_{3}$ & -459.58199 & 102.28 & -459.41907 & 2.3963 & 1.80237 & 1.48389 & 1.27787 \\
\hline
\end{tabular}




\begin{tabular}{|c|c|c|c|c|c|}
\hline \multicolumn{6}{|c|}{$\begin{array}{c}\text { TABLE-2 } \\
\text { RELATIVE ENGERIES OF THE INTERMEDIATE SPECIES OF ETHYLENE GLYCOL- } \mathrm{H}_{2} \mathrm{O} \text { SYSTEM }\end{array}$} \\
\hline Species & $\mathrm{D}_{\mathrm{e}}^{\mathrm{a}}(\mathrm{kcal} / \mathrm{mol})$ & $\mathrm{D}_{\mathrm{e} 0}{ }^{\mathrm{b}}(\mathrm{kcal} / \mathrm{mol})$ & Species & $\mathrm{D}_{\mathrm{e}}^{\mathrm{a}}(\mathrm{kcal} / \mathrm{mol})$ & $\mathrm{D}_{\mathrm{e} 0}^{\mathrm{b}}(\mathrm{kcal} / \mathrm{mol})$ \\
\hline $1(1)$ & 0.0000 & 0.0000 & $10(10)$ & 0.0000 & 0.0000 \\
\hline $2(1+1)$ & -8.0195 & -6.1119 & $11(1+10)$ & -5.6726 & -4.6247 \\
\hline $3(3)$ & 0.0000 & 0.0000 & $12(1+1+10)$ & -17.0493 & -13.7737 \\
\hline $4(3+3)$ & $\begin{array}{l}-6.4467 \\
-6.0^{\mathrm{b}}\end{array}$ & $\begin{array}{l}-3.9345 \\
-4.95(\text { exptl. })^{\mathrm{c}} \\
-3.7^{\mathrm{d}}\end{array}$ & $13(3+10)$ & -5.2559 & -3.7380 \\
\hline $5(3+3+3)$ & -19.1793 & -12.9762 & $14(3+3+10)$ & -15.8527 & -11.2016 \\
\hline $6(1+1+3)$ & $\begin{array}{l}-19.8103 \\
-17.9^{\mathrm{d}}\end{array}$ & $\begin{array}{l}-14.4577 \\
-12.1^{\mathrm{d}}\end{array}$ & $15(1+1+3+10)$ & -29.61191 & -23.3871 \\
\hline $7(1+3)$ & -9.0047 & -6.2311 & $16(1+3+10)$ & -17.7144 & -13.0082 \\
\hline $8(1+3+3)$ & -19.3773 & -13.4474 & $17(1+3+3+10)$ & -27.7688 & -20.2621 \\
\hline $9(1+3+3+3)$ & -34.1550 & -25.1692 & & & \\
\hline
\end{tabular}

Calculated binding energy results show that the $-\mathrm{D}_{\mathrm{e} 0}$ value for the most stable ethylene glycol dimer is determined at $6.1119 \mathrm{kcal} / \mathrm{mol}$ (Table-2) corrected by ZPE. As one observes in Fig. 1 (2) the most stable dimer configuration consist of two ethylene glycol monomers connected by bifurcated hydrogen bonds and forming a cyclic structure.

In Table-1, the total dipole moments for the geometries optimized with the same basis set are listed for conformers along with the experimentally determined dipole moments. In this work, the dipole moment of ethylene glycol dimer is found at $1.7182 \mathrm{D}$, which can be due to the dipole-dipole interaction and hydrogen bonds between two ethylene glycol molecules.

From Table-3, we can find that the calculational stretching and bending vibrational frequencies are in good agreement with our previous experimental results ${ }^{12,13}$.

$\mathrm{H}_{2} \mathrm{O}$ monomer, $\mathrm{H}_{2} \mathrm{O}$ dimer and $\mathrm{H}_{2} \mathrm{O}$ trimer: A schematic representation of the optimized structures and the calculational $\mathrm{H} \cdots \mathrm{O}$ bond lengths $(\AA)$ of $\mathrm{H}_{2} \mathrm{O}$ monomer, $\mathrm{H}_{2} \mathrm{O}$ dimer and $\mathrm{H}_{2} \mathrm{O}$ trimer are shown in Fig. 1 (3, 4 and 5). The intermolecular $\mathrm{H} \cdots \mathrm{O}$ bond length in the $\mathrm{H}_{2} \mathrm{O}$ dimer is calculated as $1.9063 \AA$ in this work, which were reported at $1.903 \AA$ (DFT/MBP functional $^{25}$ and $1.970 \AA$ (B3LYP functional $)^{26}$. The intermolecular $\mathrm{H} \cdots \mathrm{O}$ bond lengths in the $\mathrm{H}_{2} \mathrm{O}$ trimer are calculated at $1.8699,1.8706$ and $1.8985 \AA$, which are in agreement with reported work ${ }^{27}(1.882 \AA, 1.883 \AA$ and $1.909 \AA$ at the B3LYP/ $6-31+\mathrm{G}(\mathrm{d}, \mathrm{p})$ level) and reported values ${ }^{28}(1.854 \AA, 1.858 \AA$ and $1.994 \AA$ at the MP2 functional).

The total energies and the corresponding ZPE corrections for the $\mathrm{H}_{2} \mathrm{O}$ monomer, $\mathrm{H}_{2} \mathrm{O}$ dimer and $\mathrm{H}_{2} \mathrm{O}$ trimer are listed in Table- 1 . And the corresponding $-\mathrm{D}_{\mathrm{e}}$ and $-\mathrm{D}_{\mathrm{e} 0}$ values are listed in Table-2. For the $\mathrm{H}_{2} \mathrm{O}$ dimer, the $-\mathrm{D}_{\mathrm{e} 0}$ value of $3.9345 \mathrm{kcal} /$ mol agrees with the calculational result of $3.7 \mathrm{kcal} / \mathrm{mol}^{27}$ and the widely accepted experimental value of $3.59 \pm 0.5 \mathrm{kcal} /$ $\mathrm{mol}^{29}$. The calculated $-\mathrm{D}_{\mathrm{e} 0}$ value of $12.9762 \mathrm{kcal} / \mathrm{mol}$ for the $\mathrm{H}_{2} \mathrm{O}$ trimer is in agreement with the published average value of $12.93 \mathrm{kcal} / \mathrm{mol}^{30}$.

From Table-1, it is worth to point out the DFT values obtained for the dipole moments of these clusters in this work: the moment value of $\mathrm{H}_{2} \mathrm{O}$ monomer is $2.2491 \mathrm{D}$; the moment value of the $\mathrm{H}_{2} \mathrm{O}$ dimer is $2.9007 \mathrm{D}$; and the moment value of the $\mathrm{H}_{2} \mathrm{O}$ trimer is $1.2346 \mathrm{D}$.
The calculated harmonic vibrational frequencies are summarized in Table- 3 for the $\mathrm{H}_{2} \mathrm{O}$ monomer, the $\mathrm{H}_{2} \mathrm{O}$ dimer and the $\mathrm{H}_{2} \mathrm{O}$ trimer and compared with the experimental values for $\mathrm{H}_{2} \mathrm{O}^{13,31,32}$. The calculated results are found at $1662 \mathrm{~cm}^{-1}$ in the $\mathrm{H}_{2} \mathrm{O}$ monomer, at $1675 \mathrm{~cm}^{-1}$ in the $\mathrm{H}_{2} \mathrm{O}$ dimer and at 1679 $\mathrm{cm}^{-1}$ in the $\mathrm{H}_{2} \mathrm{O}$ trimer. The theoretical approach predicts also a sizeable blue shift (19-36 $\left.\mathrm{cm}^{-1}\right)$ for $\mathrm{H}-\mathrm{O}-\mathrm{H}$ bending frequencies involving the hydrogen bonds.

$(\mathrm{EG})_{2}-\mathrm{H}_{2} \mathrm{O}, \mathrm{EG}-\mathrm{H}_{2} \mathrm{O}, \mathrm{EG}-\left(\mathrm{H}_{2} \mathrm{O}\right)_{2}$ and EG- $\left(\mathrm{H}_{2} \mathrm{O}\right)_{3}$ clusters: (EG) $)_{2}-\mathrm{H}_{2} \mathrm{O}, \mathrm{EG}-\mathrm{H}_{2} \mathrm{O}, \mathrm{EG}-\left(\mathrm{H}_{2} \mathrm{O}\right)_{2}$ and EG- $\left(\mathrm{H}_{2} \mathrm{O}\right)_{3}$ clusters. The optimized molecular geometries and the calculational $\mathrm{H} \cdots \mathrm{O}$ bond lengths $(\AA)$ of $(\mathrm{EG})_{2}-\mathrm{H}_{2} \mathrm{O}, \mathrm{EG}-\mathrm{H}_{2} \mathrm{O}, \mathrm{EG}-\left(\mathrm{H}_{2} \mathrm{O}\right)_{2}$ and EG$\left(\mathrm{H}_{2} \mathrm{O}\right)_{3}$ clusters are shown in Fig. 1 (6-9). In this work, the intramolecular $\mathrm{H}$... O bond lengths in ethylene glycol molecules are calculated at $2.8639 \AA$ in $(\mathrm{EG})_{2}-\mathrm{H}_{2} \mathrm{O}$, at $2.8358 \AA$ in EG$\mathrm{H}_{2} \mathrm{O}$ (2.84 A calculated at the DFT B3LPY/6-311g (3df, 3pd) level $)^{24}$, at $2.8434 \AA$ in EG- $\left(\mathrm{H}_{2} \mathrm{O}\right)_{2}$ and at $2.8039 \AA$ in EG$\left(\mathrm{H}_{2} \mathrm{O}\right)_{3}$. Meanwhile, the intermolecular $\mathrm{H} \cdots \mathrm{O}$ bond lengths between ethylene glycol and $\mathrm{H}_{2} \mathrm{O}$ in $\mathrm{EG}-\mathrm{H}_{2} \mathrm{O}$ are calculated at $1.7429 \AA$ to $2.0096 \AA$.

The $-\mathrm{D}_{\mathrm{e} 0}$ value for $\mathrm{EG}-\mathrm{H}_{2} \mathrm{O}$ is of $6.2311 \mathrm{kcal} / \mathrm{mol}$, which is stronger than the $-\mathrm{D}_{\mathrm{e} 0}$ values for the ethylene glycol dimer $(6.1119 \mathrm{kcal} / \mathrm{mol})$ and the $\mathrm{H}_{2} \mathrm{O}$ dimer $(3.9345 \mathrm{kcal} / \mathrm{mol})$. Meanwhile, the $-\mathrm{D}_{\mathrm{e} 0}$ values for $(\mathrm{EG})_{2}-\mathrm{H}_{2} \mathrm{O}$ (about $\Phi_{1}=87 \%$ ) is $14.4577 \mathrm{kcal} / \mathrm{mol}$, for EG- $\left(\mathrm{H}_{2} \mathrm{O}\right)_{2}$ (about $\Phi_{1}=60 \%$ ) is $13.4474 \mathrm{kcal} / \mathrm{mol}$ and for EG- $\left(\mathrm{H}_{2} \mathrm{O}\right)_{3}$ (abut $\left.\Phi_{1}=50 \%\right)$ is $25.1692 \mathrm{kcal} / \mathrm{mol}$.

The calculated and experimental spectral data for ethylene glycol $+\mathrm{H}_{2} \mathrm{O}$ system are summarized in Table-3. The calculated $\mathrm{H}-\mathrm{O}-\mathrm{H}$ bending vibration frequences are found at $1694 \mathrm{~cm}^{-1}$ in the EG- $\mathrm{H}_{2} \mathrm{O}$, at $1667 \mathrm{~cm}^{-1}$ in the EG- $\left(\mathrm{H}_{2} \mathrm{O}\right)_{2}$ and at $1694 \mathrm{~cm}^{-1}$ in the EG- $\left(\mathrm{H}_{2} \mathrm{O}\right)^{3}$.

Compared with the previous results, the calculational results of the ethylene glycol clusters and $\mathrm{H}_{2} \mathrm{O}$ clusters are in agreement with the reportedly calculational and experimental results. From the binding energies, calculated IR spectra, dipole moments and rotational constants, the B3LYP/6-31G + (d) level can be used for the calculation of the ethylene glycol + $\mathrm{H}_{2} \mathrm{O}+\mathrm{SO}_{2}$ system.

For $\mathrm{H}_{2} \mathrm{O}$ system, the theoretical approach predicts that it is more difficult to induce $\mathrm{H}-\mathrm{O}-\mathrm{H}$ bending vibration in $\mathrm{H}_{2} \mathrm{O}$ when the hydrogen bonds are formed among $\mathrm{H}_{2} \mathrm{O}$ molecules. 


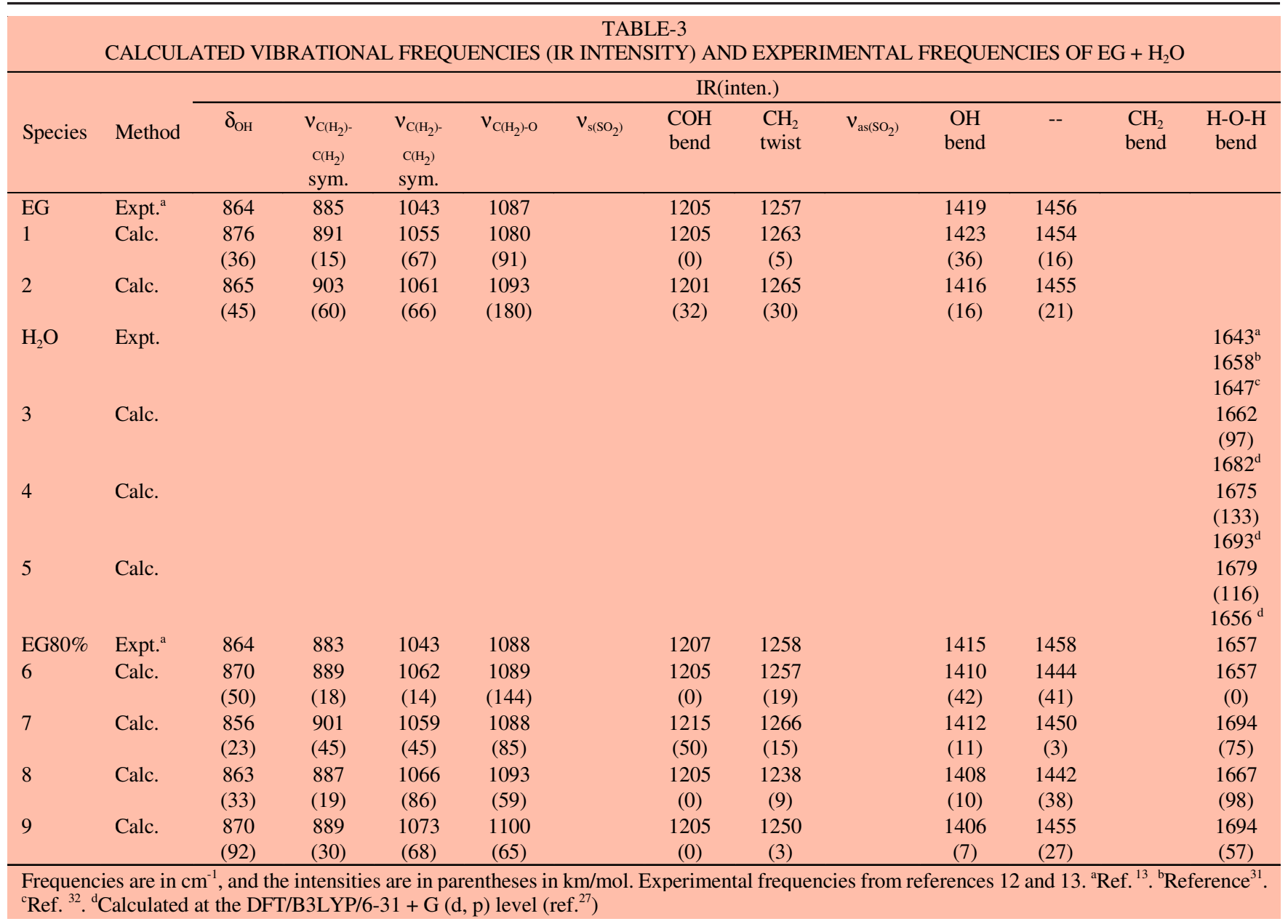

So it needs more energy, i.e. the higher frequency to force the $\mathrm{H}-\mathrm{O}-\mathrm{H}$ bending vibration. (2) For the ethylene glycol $+\mathrm{H}_{2} \mathrm{O}$ system, the intramolecular $\mathrm{H} \cdots \mathrm{O}$ bonds lengths of ethylene glycol in $(\mathrm{EG})_{2}-\mathrm{H}_{2} \mathrm{O}$, EG- $\mathrm{H}_{2} \mathrm{O}$, EG- $\left(\mathrm{H}_{2} \mathrm{O}\right)_{2}$ and EG- $\left(\mathrm{H}_{2} \mathrm{O}\right)_{3}$ clusters are longer than in the ethylene glycol monomer and in the ethylene glycol dimmer, maybe, those phenomena result from the hydrogen bonding between ethylene glycol and $\mathrm{H}_{2} \mathrm{O}$ molecules. In addition, the previously intramolecular hydrogen bond length of ethylene glycol molecule in the ethylene glycol$\mathrm{H}_{2} \mathrm{O}$ cluster is of $2.8358 \AA$, value for which we can consider the ethylene glycol intramolecular hydrogen bonds as disrupted.

The $-\mathrm{D}_{\mathrm{e} 0}$ value for ethylene glycol- $\mathrm{H}_{2} \mathrm{O}$ is higher than the values for ethylene glycol dimer and for $\mathrm{H}_{2} \mathrm{O}$ dimer, which can help to claim that the addition of $\mathrm{H}_{2} \mathrm{O}$ can destroy the original intermolecular hydrogen bonds among ethylene glycol molecules and ethylene glycol can be easily solved in water. From above $-\mathrm{D}_{\mathrm{e} 0}$ values, we can see that $(\mathrm{EG})_{2}-\mathrm{H}_{2} \mathrm{O}$ owns higher $-\mathrm{D}_{\mathrm{e} 0}$ value than EG- $\left(\mathrm{H}_{2} \mathrm{O}\right)_{2}$ and the results can help us to explain our previous experimental results ${ }^{13}$ and explore the various volume fraction aqueous solution of ethylene glycol's absorption capacities to $\mathrm{SO}_{2}$. Although ethylene glycol has a propensity toward internal hydrogen bonds ${ }^{28}$, water can efficiently bind with ethylene glycol to disrupt the intramolecular hydrogen bond in the ethylene glycol monomer.

Ethylene glycol is a relatively simple molecule, but its condensed phase structures are quite complicated. Previous studies ${ }^{33}$ have shown that ethylene glycol has numerous stable conformations and that can be observed on vibrational spectra. Therefore, the IR spectra of ethylene glycol might have contributions from different conformations and different hydrogen bonding structures as a function of mole fraction in solution. The experimental IR measurements ${ }^{12}$ show an increase in the wavenumber (blue shift) with increasing water concentration in the aqueous solution of ethylene glycol. Previous spectroscopic studies ${ }^{34}$ of methanol-water solutions revealed a similar phenomenon when methanol acts as a hydrogen-bond acceptor. In addition to the comparisons of spectral intensity, a blue shift of the symmetric stretch frequencies is observed in both the calculated and experimental results and hydrogen bonds between ethylene glycol and water within ethylene glycol + $\mathrm{H}_{2} \mathrm{O}$ clusteres as opposed to intramolecular ethylene glycolethylene glycol hydrogen bonds as water is added to the solution $^{35}$. These results and comparisons suggest that in addition to hydrogen bonding with itself, ethylene glycol can form hydrogen-bonded clusteres with water.

\section{Conclusion}

The intramolecular $\mathrm{H} \cdots \mathrm{O}$ bond lengths in ethylene glycol molecules are calculated at $2.8639 \AA$ in $(\mathrm{EG})_{2}-\mathrm{H}_{2} \mathrm{O}$, at 2.8358 $\AA$ in $\mathrm{EG}-\mathrm{H}_{2} \mathrm{O}$, at $2.8434 \AA$ in EG- $\left(\mathrm{H}_{2} \mathrm{O}\right)_{2}$ and at $2.8039 \AA$ in EG- $\left(\mathrm{H}_{2} \mathrm{O}\right)_{3}$. Meanwhile, the intermolecular $\mathrm{H} \cdots \mathrm{O}$ bond lengths between ethylene glycol and $\mathrm{H}_{2} \mathrm{O}$ in ethylene glycol $+\mathrm{H}_{2} \mathrm{O}$ are calculated at $1.7429 \AA$ to $2.0096 \AA$. The calculated $-\mathrm{D}_{\mathrm{e} 0}$ value for $(\mathrm{EG})_{2}-\mathrm{H}_{2} \mathrm{O}$ (about $87 \%$ aqueous solution of ethylene 
glycol) is $14.4577 \mathrm{kcal} / \mathrm{mol}$, for EG- $\left(\mathrm{H}_{2} \mathrm{O}\right)_{2}$ (about $\left.\Phi_{1}=60 \%\right)$ is $13.4474 \mathrm{kcal} / \mathrm{mol}$ and for EG- $\left(\mathrm{H}_{2} \mathrm{O}\right)_{3}$ (about $\left.\Phi_{1}=50 \%\right)$ is $25.1692 \mathrm{kcal} / \mathrm{mol}$. The addition of $\mathrm{H}_{2} \mathrm{O}$ can destroy the original intermolecular hydrogen bonds in ethylene glycol system and ethylene glycol can be easily solved in water.

\section{ACKNOWLEDGEMENTS}

This work was supported by the National Natural Science Foundation of China (21166017), Program for New Century Excellent Talents in University (NCET-12-1017), the Research Fund for the Doctoral Program of Higher Education of China (20111514120002), the Natural Science Foundation of Inner Mongolia Autonomous Region (2011BS0601), the Program for Grassland Excellent Talents of Inner Mongolia Autonomous Region, Inner Mongolia Autonomous Region's Educational Commission (NJZZ11068), Program for Young Talents of Science and Technology in Universities of Inner Mongolia Autonomous Region (NJYT-12-B13), the Inner Mongolia Talented People Development Fund and Yongfeng Boyuan Industry Co., Ltd. (Jiangxi Province, China).

\section{REFERENCES}

1. X. Esteve, A. Conesa and A. Coronas, J. Chem. Eng. Data, 48, 392 (2003)

2. H.C. Ku and C.H. Tu, J. Chem. Eng. Data, 45, 391 (2000).

3. A. Valtz, C. Coquelet and D. Richon, Fluid Phase Equilib., 220, 75 (2004).

4. D. Nagel, R. De Kermadec, H.G. Lintz, C. Roizard and F. Lapicque, Chem. Eng. Sci., 57, 4883 (2002).

5. R. De Kermadec, F. Lapicque, D. Roizard and C. Roizard, Ind. Eng. Chem. Res., 41, 153 (2002).

6. C.N. Schubert and W.I. Echter, The Method of Polymer Ethylene Glycol for Removal Pollution from Gases, CN Patent 1364096A (2002).

7. X.X. Li, Y.X. Liu and X.H. Wei, Chin. J. Chem. Eng., 13, 234 (2005).

8. X.H. Wei, CN Patent, 02130605,2 (2002).

9. X.H. Wei, J.B. Zhang and P.Y. Zhang, Removal of SOx from Flue Gas by Ethylene Glycol, CN Patent 101053746 (2007).

10. J.B. Zhang, P.Y. Zhang, G.H. Chen, F. Han and X. Wei, J. Chem. Eng. Data, 53, 1479 (2008)
11. J.B. Zhang, P.Y. Zhang, F. Han, G. Chen, R. Deng and X. Wei, J. Chem. Eng. Data, 53, 2372 (2008).

12. J.B. Zhang, P.Y. Zhang, K. Ma, F. Han, G.H. Chen and X.H. Wei, Sci. China Ser. Biol. Chem., 51, 420 (2008).

13. J.B. Zhang, P.Y. Zhang, F. Han, G. Chen, L. Zhang and X. Wei, Ind. Eng. Chem. Res., 48, 1287 (2009).

14. E. Potteau, E. Levillain and J.P. Lelieur, J. Electroanal. Chem., 476, 15 (1999).

15. M.H.H. van Dam, A.S. Lamine, D. Roizard, P. Lochon and C. Roizard, Ind. Eng. Chem. Res., 36, 4628 (1997).

16. P. Ivopoulos, M. Sotiropoulou, G. Bokias and G. Staikos, Langmuir, 22, 9181 (2006).

17. L. Radom, W.A. Lathan, W.J. Hehre and J.A. Pople, J. Am. Chem. Soc., 95, 693 (1973).

18. Y. Elkadi and L. Adamowicz, Chem. Phys. Lett., 261, 507 (1996).

19. P.Manivet and M. Masella, Chem. Phys. Lett., 228, 642 (1998).

20. D. Christen, L.H. Coudert, J.A. Larsson and D. Cremer, J. Mol. Spectrosc., 205, 185 (2001).

21. T. Oie, I.A. Topol and S.K. Burt, J. Phys. Chem., 98, 1121 (1994).

22. D.L. Howard, P. Jørgensen and H.G. Kjaergaard, J. Am. Chem. Soc., 127, 17096 (2005).

23. H.S.P. Müller and D. Christen, J. Mol. Spectrosc., 228, 298 (2004).

24. O.V. de Oliveira and L.C. Gomide Freitas, J. Mol. Struct., 728, 179 (2005).

25. X.P. Long, J.B. Nicholas, M.F. Guest and R.L. Ornstein, J. Mol. Struct., 412, 121 (1997).

26. X. Xu and W.A. Goddard, J. Phys. Chem. A, 108, 2305 (2004).

27. L. González, O. Mó, M. Yáñez and J. Elguero, J. Mol. Struct., 371, 1 (1996).

28. C.J. Cramer and D.G. Truhlar, J. Am. Chem. Soc., 116, 3892 (1994).

29. L.A. Curtiss, D.J. Frurip and M.J. Blander, Chem. Phys., 71, 2703 (1979).

30. G.I. Csonka, A. Ruzsinszky and J.P. Perdew, J. Phys. Chem. B, 109, 21471 (2005)

31. L.M. Goss, S.W. Sharpe, T.A. Blake, V. Vaida and J.W. Brault, J. Phys. Chem. A, 103, 8620 (1999).

32. B. Zelent, N.V. Nucci and J.M. Vanderkooi, J. Phys. Chem. A, 108, 11141 (2004).

33. K.S. Alongi, T.S. Dibble, G.C. Shields and K.N. Kirschner, J. Phys. Chem. A, 110, 3686 (2006).

34. G. Ma and H.C. Allen, J. Phys. Chem. B, 107, 6343 (2003).

35. E.L. Hommel, J.K. Merle, G. Ma, C.M. Hadad and H.C. Allen, J. Phys. Chem. B, 109, 811 (2005).

36. M.A. Murcko and R. Dipaola, J. Am. Chem. Soc., 114, 10010 (1992).

37. Y. Sakai, M. Koyanagi, K. Mogi and E. Miyoshi, Surf. Sci., 513, 272 (2002). 